\title{
International trade and exchange rate volatility*
}

\author{
Jean-Marie Viaene
}

Erasmus Universiteit Rotterdam, Rotterdam, The Netherlands

Casper G. de Vries

Katholieke Universiteit Leuven, B-3000 Louvain, Belgium

Received September 1989, final version received May 1991

For currencies with well developed forward markets several papers have investigated the conjectured negative relationship between trade and short term exchange rate volatility, without being very successful. A theoretical explanation for the empirical anomalies is provided by solving explicitly for the forward rate. Because importers and exporters are on opposite sides of the forward market, so is their exposure towards exchange rate volatility. Moreover, which trade flow benefits and which one loses from increased volatility is determined by the signs of the aggregate net foreign currency exposure and the aggregate measure of risk aversion.

\section{Introduction}

Since the advent of flexible exchange rates in 1973 great interest has been shown in the impact of exchange rate variability on the volume of international trade. Central to the issue is the popular conjecture of a negative efiect. The proposition has been considered in mary empirical studies. $^{1}$ The evidence differs depending on whether a well developed forward market does or does not exist for the currency contract under

Correspondence to: Casper G. de Vries, Center for Economic Studies, Katholieke Universiteit Leuven, E van Evenstraat 2B, B-3000 Louvain, Belgium.

*We received fruitful comments from V. Argy, O. Biernaux, H. Dellas, J.W. Grunning, J. Melitz, J. Stein, P. Reding, and the participants of the seminars at the Universiteit van Amsterdam, CEPS (Brussels) and the Bologna meeting of the EEA. The suggestions of J.P. Neary and an anonymous referee considerably improved the presentation of the results.

${ }^{1}$ See e.g. Brada and Mendez (1988), Hooper and Kohlhagen (1978), Coes (1981), Cushman (1983, 1986), Gotur (1985), Kenen and Rodrik (1984, 1986), Bailey et al. (1986), Thursby and Thursby (1987), De Grauwe and Bellefroid (1987), De Grauwe and Verfaille (1988) and Steinherr and Perée (1989). 
consideration. In the former case no consistent link between volatility and trade has been found. Regression coefficients for the volatility effect on trade are of either sign and are sometimes significantly different from zero and sometimes not. However, for many of the developing countries currencies and for most longer term currency contracts efficient forward markets are absent. In this case there is some unequivocal evidence of a negative relationship. One respect in which all studies do corroborate the theory, is the effect of changes in the mean of the exchange rate. Here one finds that the conventional terms of trade predictions are confirmed.

The aim of the paper is to advance a theoretical explanation for the empirical anomaly with regard to the relationship between the volume of trade and exchange rate volatility in the presence of well developed forward markets. The analysis starts with the celebrated separation theorem. Ethier (1973) showed that if a firm optimizes over its cutput level and the size of the hedge, the output level only depends on the forward rate, while the hedge is also a function of the risk premium. Hence $\epsilon:$ shange rate volatility only affects the hedging decision. This message has been reiterated by several authors. ${ }^{2}$ Nonetheless the empirical studies quoied in footnote 1 presume a fixed relationship between the output level and the hedge. These studies therefore erroneously presuppose a negative effect of volatility on exports and imports, see Holthausen (1979, p. 992). The channel through which volatility does affect trade under proper optimization, however, is more indirect. When the forward market clearing condition is taken into account, it is straightforward to show that volatility does affect the forward rate and thereby trade. Ethier $(1973$, p. 496$)$ already conceded that the equilibrium determination of the forward rate may alter the results. This conjecture is investigated by Kawai (1984), who derives an explicit solution for the forward rate which depends on the spot rate conditional variance. But, the literature never investigated the full scope of this equilibrium implication for trade. This paper pursues the analysis and investigates how spot rate volatility indirectly impinges upon the volume of trade. One conclusion from cur analysis is that, because exporters and importers are on opposite sides of the forward market, exchange rate volatility affects exports and imports differently. Another result is that the net currency position of the country turns out to be the crucial factur in determining the potential positive or negative effects of exchange rate volatility.

Section 2 discusses the behavior of the different market participants, and derives the equilibrium forward risk premium from the forward market clearing condition. Section 3 investigates the implications of exchange rate volatility for trade and contains the main results of this paper. Section 4 concludes.

\footnotetext{
${ }^{2}$ See e.g. Holthausen i1979), Katz and Paroush (1979), Feder et all. (1980) and Kawai (1984).
} 


\section{The forward market}

In this section we discuss the behavior of exporters, importers, speculators and the central bank in connection with the forward market. We assume that individual merchants have negligible influence on world market prices, but that domestically the demand curve is downward sloping and the supply curve is upward sloping. The way in which we model the me: iants' behavior is by means of a trade house: buying some commodities internationally and retailing them locally, or vice versa. For clarity of exposition we start with the case where all invoicing occurs in the foreign currency.

The behavior of domestic importers is discussed first. Suppose an importer faces the following inverted domestic demand function: $S=a-Y / 2$, so that the returns are: $a Y-Y^{2} / 2$, where $Y$ is the quantity demanded at price $S$. The imported commodity $Y$ costs one unit of foreign currency, hence costing $\tilde{w} Y$ in the domestic currency, where $\tilde{w}$ is the one period ahead spot foreign exchange rate, and the tilde refers to the random nature of $\tilde{w}$. As is common practice in international trade, the importer receives trade credit for one period. In order to hedge against exchange rate uncertainty, the importer may buy a forward foreign currency contract $L$ against the forward rate $f$. In sum, the importer has the following profit function:

$$
\tilde{P}=a Y-\tilde{w} Y+(\tilde{w}-f) L-\frac{1}{2} Y^{2} .
$$

In addition to the above items, one may want to include labor costs, storage costs, etc. But as long as these ccst items are linear or quadratic, eq. (1) is not affected qualitatively.

Any agent $i$ is assumed to maximize the following expected utility function: ${ }^{3}$

$$
\mathrm{E} \tilde{U}_{i}=\alpha_{i} \mathrm{E} \tilde{P}_{i}-\frac{1}{2} \alpha_{i}^{2} \operatorname{var} \tilde{P}_{i}
$$

The merchants are assumed to be risk averse, i.e. $0<\alpha_{i}<\infty$, but speculators can be risk loving, i.e. $-\infty<\alpha_{i}<0$ is allowed for below.

Returning to the case of the importer, first consider the situation when no forward market exists, i.e. $L=0$ in eq. (1). Let $\mathrm{E} \tilde{w}=\varepsilon$ and $\operatorname{var} \tilde{w}=\sigma^{2}$. Straightforward optimization yields

$$
Y=(a-\varepsilon) /\left(1+a \sigma^{2}\right) \text {. }
$$

Presumably $a>\varepsilon$. In the presence of forward markets the optimizing choices are

${ }^{3}$ In the presentation the subindex $i$ is omitted whenever no confusion is possible. 


$$
Y=a-f
$$

and

$$
L=(\varepsilon-f) / \alpha \sigma^{2}+Y,
$$

and presumably $a>f$. Note that the imports $Y$ only depend on the forward rate $f$, by the separation theorem, but that the hedge $L$ is also influenced by the degree of risk aversion $\alpha$ and the exchange rate volatility $\sigma^{2}$.

Turning to the behavior of domestic exporters we postulate a profit function:

$$
\tilde{P}=\tilde{w} X+(\tilde{w}-f) K-\mathrm{d} X-\frac{1}{2} X^{2},
$$

where $X$ is the quantity being exported and $K$ is the hedge. The exporter has some domestic purchase and production costs $\mathrm{d} X+X^{2} / 2$, which may be derived in analogy with the derivation of the importer's cost function, and sells on world markets at a price of unity. In the process, the exporter extends the customary one-period trade credit and therefore experiences some exchange rate uncertainty which may be hedged if there is a forward market. Without the possibility of hedging, the optimal export volume is

$$
X=(\varepsilon-d) /\left(1+\alpha \sigma^{2}\right) \text {. }
$$

If a forward market does exist the optimizing export and hedge levels are

$$
X=f-d,
$$

and

$$
K=(\varepsilon-f) / \alpha \sigma^{2}-X .
$$

Presumably $d<\varepsilon$ and $d<f$. Comparing eq. (5) to eq. (9), one sees that the speculative parts of the hedges, i.e. $(\varepsilon-f) / \alpha \sigma^{2}$, are similar, but that the hedge parts, i.e. $X$ and $Y$, enter with opposite signs. This latter difference stems from the simple fact that exporters expect to receive some foreign currency whereas importers have to pay in foreign currency. The sign differences on the forward rate $f$ in (4) and (8) can be explained analogously. The important conclusion is that exporters and importers take opposite hedge positions on the forward market. The speculative elements are similar, however, as both merchants have the same attitudes towards risk.

Assume that speculators try to maximize their future wealth $V(+1)$ :

$$
\widetilde{V}(+1)=(1+r) V+(\tilde{w}-f) H,
$$

by investing current wealth $V$ at the going interest rate $r$, and taking a speculative position $\mathbb{H}$ on the forward market. Substituting $\widetilde{V}(+1)$ for $\widetilde{\mathbb{P}}$ in 
eq. (2), the optimal speculative position becomes (assuming that covered interest parity holds):

$$
H=(\varepsilon-f) / \alpha \sigma^{2} \text {. }
$$

Contrary to popular belief, it does not take risk loving agents to get 'speculative' positions. In fact, if $\alpha_{i}$ of speculator $i$ is positive, eq. (11) just exhibits the risk premium: $R=\varepsilon-f$, or normal backwardation, required for speculators to take opposite positions vis-à-vis the net position of the merchants (as in the case of the insurance industry). But we do allow speculators to be risk loving, i.e. $\alpha_{i}<0$ is possible. ${ }^{4}$ This would reverse the sign of $H$.

Apart from the merchants and the speculators, the central bank is an important actor on the forward market through its forward foreign currency swaps. While different views of the central bank are possible, this is not the place to indulge into modelling its behavior explicitly. Here, we consider its forward supply of foreign currency $F$ as a parameter which is exogenous to the model.

The equilibrium forward rate $f$ can now be easily derived from the forward market clearing condition

$$
\sum_{i=1}^{n} L_{i}+\sum_{i=1}^{m} K_{i}+\sum_{i=1}^{s} H_{i}-F=0
$$

where $n, m$ and $s$ are the number of importers, exporters and speculators respectively. Define the trade balance $T B$ as the difference between exports and imports

$$
T B=\sum_{i=1}^{m} X_{i}-\sum_{i=1}^{n} Y_{i}
$$

Let $\Omega=1 / \sum_{i=1}^{n+m+s}\left(1 / \alpha_{i}\right)$ be the aggregate measure of risk aversion, i.e. $1 / \Omega$ equals the sum of the reciprocal measures of individual risk aversion. [If $\alpha_{i}=\alpha$ for all $i$, then $\Omega=\alpha /(n+m+s)$.] Note that $\Omega$ can be of either sign due to the fact that we allow speculators to be risk loving. ${ }^{5}$ Now substitute eqs. (5), (9) and (11) into eq. (12) and use eq. (13) to find the equilibrium risk premium $(1 / \Omega \neq 0)$

\footnotetext{
${ }^{4}$ The case of risk neutrality is not entertained as this reduces $\mathbb{R}$ to zero and hence there will be no effecis of volatility on trade. Most empirical evidence suggests that $\mathbb{R}$ is monzero.

${ }^{5}$ Apart from the different attitude towards risk we could easily allow for diverse precisions as well, see e.g. Stein (1985), but as this has no qualitative implications, and as it reduces the transparency of exposition, we do not present this case.
} 


$$
R=\Omega \sigma^{2}[T B+F]
$$

If the happenstance $1 / \Omega=0$ arises, then $T B+F=0$. Note that, by definition, $R=R(f)=\varepsilon-f$, and by using eqs. (4) and (8) in eq. (13) it follows that

$$
T B=T B(f)=(m+n) f-\sum_{i=1}^{m} d_{i}-\sum_{i=1}^{n} a_{i} .
$$

Thus $k$, th the risk premium and the trade balance are linear functions of $f$. Hence the equilibrium forward rate can be easily computed from eq. (14), if desired. In general the risk premium $R$ is a function of the thinness of the forward market, the trade balance, the attitudes towards risk and the spot rate volatility. Intuition as to how these factors influence $R$ is easily established by inspecting extreme cases. For example, if the number of speculators $s$ tends to infinity, or $T B+F$ equals zero, or $\Omega$ tends to zero, or $\sigma^{2}$ tends to zero, the risk premium $R$ disappears.

At the close of this section we briefly consider the case where only a proportion $\lambda, 0<\lambda<1$, of imports and a proportion $\gamma, 0<\gamma<1$, of exports are denominated in the foreign currency, the rest being denominated in the domestic currency [Viaene and De Vries (1992)]. Define FTB as the proportion of the trade balance that is denominated in the foreign currency:

$$
F T B=\sum_{i=1}^{m} \gamma_{i} X_{i}-\sum_{i=1}^{n} \lambda_{i} Y_{i}
$$

After appropriate modification of the profit functions, optimization and substitution of the demand schedules for forward foreign currency into eq. (12), one obtains the modified risk premium

$$
R=\Omega \sigma^{2}[F T B+F]
$$

Eq. (15) resembles eq. (14), the only change is the use of the country's net foreign currency position $F T B$ instead of the balance of trade. The relationship between $T B$ and $F^{\top} B$ is governed by Grassman's law (1973) which posits that $\gamma \leqq \lambda$. Thus if $T B<0$, then $F T B<0$ as well. But if $T B>0$, then $F B$ is not necessarily positive.

The following lemma summarizes the results of this section in terms of the risk premium and the aggregate currency position.

Lemma 1. In the absence of official intervention, $F=0$, with complete foreign currency invoicing $\operatorname{sign}(R)=\operatorname{sign}(\Omega) \cdot \operatorname{sign}(T B)$, and with partial foroign currency invoicing $\operatorname{sign}(\mathbb{R})=\operatorname{sign}(\Omega) \cdot \operatorname{sign}(F T B)$. 
The next section exploits Lemma 1 to investigate the relationship between the spot rate volatility $\sigma^{2}$, the trade volumes $X, Y$, and $T B$ or $F T B$.

\section{Exchange rate volatility and trade}

We start the investigation into the connection between trade and exchange rate volatility by considering the case with no well developed forward market. Recall eqs. (3) and (7) and assume for simplicity that all merchants are equally risk averse, $\alpha_{i}=\alpha$, and that all invoicing occurs in the foreign currency. From eqs. (3), (7) and (13) it is then immediate that

$$
-\frac{\partial Y}{\partial \varepsilon}=\frac{\partial X}{\partial \varepsilon}=\frac{1}{m+n} \frac{\partial T B}{\partial \varepsilon}=\frac{1}{1+\alpha \sigma^{2}}>0,
$$

and

$$
\begin{aligned}
& \frac{\partial Y}{\partial \sigma^{2}}=-\frac{\alpha Y}{1+\alpha \sigma^{2}}<0, \quad \frac{\partial X}{\partial \sigma^{2}}=-\frac{\alpha X}{1+\alpha \sigma^{2}}<0, \\
& \frac{\partial T B}{\partial \sigma^{2}}=-\frac{\alpha T B}{1+\alpha \sigma^{2}} .
\end{aligned}
$$

We have the following result.

Pruposition 1. In the absence of forward markets, a change in the mean exchange rate affects trade flows and the balance of trade as predicted by the conventional terms of trade analysis. An increase in exchange rate volatility reduces both imports and exports, and the surplus or deficit of the balance of trade is reduced as well.

The analyses by Coes (1981) and Perée and Steinherr (1989) for example satisfy the assumptions of the proposition and their results corroborate the theoretical predictions. ${ }^{6}$

Let us investigate how Proposition 1 has to be modified when forward markets are present. From the eqs. (4), (8), (13) and the definition of $R$ we derive the following lemma.

Lemma 2. In the presence of a forward market $\partial Y_{i} / \partial f=-1, \partial X_{i} / \partial f=1$, $\partial T B / \partial f=m+n$ and $\partial R / \partial f=-1$.

\footnotetext{
${ }^{6} \mathrm{~A}$ recent contribution by Dellas and Zilberfarb (1990) argues, however, that outside the class of quadratic utility functions the negative volatility effect may depend on the value of the measure of risk aversion.
} 
Now note that the only channel through which changes in the expected exchange rate or the volatility of the exchange rate can affect trade volumes is through the forward rate $f$. Together with Lemma 2 this observation establishes:

Proposition 2. With a forward market, one trade flow benefits and the other trade flow necessarily loses from changes in either the expected rate or the volatility. Formally: $\partial X_{i} / \partial \varepsilon=-\partial Y_{j} / \partial \varepsilon$, and $\partial X_{i} / \partial \sigma^{2}=-\partial Y_{j} / \partial \sigma^{2}$ for all $i=$ $1, \ldots, m$ and $j=1, \ldots, n$.

The effects of changes in the expected rate just corroborate eq. (16) and Proposition 1. The striking implication of Proposition 2 is, however, that the effects of a change in volatility on imports and exports are opposite to each other, which is in sharp contrast to the conventional wisdom expressed in the conjecture at the outset and as maintained in Proposition 1. The intuition behind the opposite effects is that importers and exporters are on opposite sides of the forward market as exhibited by eqs. (4), (5) and (8), (9).

It is of interest to derive explicit expressions for the partial derivatives in Proposition 2. Note that $\partial R / \partial \varepsilon=1$. Differentiate eq. (14) or eq. (15) with respect to $f$ and use the chain rule. This yields the following results.

Proposition 3. With a forward market ${ }^{7}$

$$
\frac{\partial X}{\partial \varepsilon}=-\frac{\partial Y}{\partial \varepsilon}=\frac{1}{m+n} \frac{\partial T B}{\partial \varepsilon}=\frac{1}{1+(m+n) \Omega \sigma^{2}},
$$

and

$$
\frac{\partial X}{\partial \sigma^{2}}=-\frac{\partial Y}{\partial \sigma^{2}}=\frac{1}{m+n} \frac{\partial T B}{\partial \sigma^{2}}=\frac{-\Omega[T B+F]}{1+(m+n) \Omega \sigma^{2}} .
$$

Corollary 1. With partial foreign currency invoicing the conclusions of Proposition 3 remain valid if $T B$ is replaced by FTB, i.e. the part of the TB that is denominated in the foreign currency.

To obtain the conventional terms of trade effects eq. (18) shows it is necessary and sufficient that $\Omega>-1 /(m+n) \sigma^{2}$. A sufficient condition for this is that all agents are risk averse. Under the latter supposition it follows from eq. (19) and Lemma 1 that with zero official intervention, $F=0$, exports lose (benefit) and imports benefit (lose) whenever the balance of trade is positive (negative), or alternatively whenever the forward risk premium is positive (negative). The fact that TB determines which flow benefits stems from the

${ }^{7}$ All partials are zero for the happenstance that $1 / \Omega=0$. 
equilibrium feature of the forward rate, i.e. the total supply and demand for forward foreign currency determine the forward rate. If, however, $\Omega$ is negative due to the dominance of risk loving speculators, or if official intervention $F$ is noizero, then one must rely on eqs. (18) and (19) to find out which trade flow benefits. This notwithstanding we have the robust result of Proposition 2.

Most of the empirical studies report insignificant coefficients for the volatility variable in a large number of cases. This is not so surprising, given that $T B$ repeatedly reversed sign for the countries under consideration. ${ }^{8}$ Consider e.g. the cases of the bilateral trade flows between the U.K., France and the U.S. as reported in Cushman (1988, p. 324 and p. 327). Another example is the significantly positive coefficient on the risk variable which is reported in several of the studies for U.S. exports to Japan. This latter finding is consistent with the unequivosal Japanese trade surplus over the sample and the fact that a large part of Japancse trade is conducted in U.S. dollars, see Black (1985, p. 1159).

Thus far we have not paid much attention to the forward intervention $F$ by the central bank. This term may not be unimportant as can be seen from eq. (19). Because $T B$ or $F T B$ give the net foreign currency position, $F$ has the same order of magnitude. ${ }^{9}$ Hence, forward intervention may alter the sign of $T B$ and thereby switch the signs of the partials in eq. (19). The presence of $F$ points towards some additional theoretical insights. Up to this point we have considered the changes in $\varepsilon$ and $\sigma^{2}$ as exogenously given. One way in which the 2 changes can be engineered is through official intervention $F$. To make this point, let $\varepsilon_{F}$ and $\sigma_{F}^{2}$ denote the partial derivatives of $\varepsilon$ and $\sigma^{2}$ with respect to $F$. Differentiate eq. (14) io obtain

$$
\frac{\mathrm{d} f}{\mathrm{~d} F}=\frac{\partial f}{\partial F}+\frac{\partial f}{\partial \varepsilon} \varepsilon_{F}+\frac{\partial f}{\partial \sigma^{2}} \sigma_{F}^{2}=\frac{-\Omega \sigma^{2}+\varepsilon_{F}-\Omega[T B+F] \sigma_{F}^{2}}{1+(m+n) \Omega \sigma^{2}}
$$

Consider the special case of a mean preserving spread change, then

$$
\frac{\mathrm{d} f}{\mathrm{~d} F}=\frac{-\Omega \sigma^{2}}{1+(m+n) \Omega \sigma^{2}}\left[1+\frac{T B+F}{F} \phi\right]
$$

where $\phi$ is the volatility elasticity of official intervention. To interpret this expression, suppose all agents are risk averse, $\Omega>0$, so that the factor in

\footnotetext{
${ }^{8}$ There may be other econometric causes for the poor fit. For example, Pagan (1984, p. 235, 236) shows that as $\sigma^{2}$ is a generated regressor, this may well bias the estimates. Moreover, the nonlinearity of $Y$ and $X$ with respect to $\sigma^{2}$ may vitiate linear estimation.

${ }^{\mathbf{9}}$ From the IMF International Financial Statistics tables, quite often the change in reserves matches the trade balance in magnitude.
} 
front of the square brackets is negative. Let intervention $F$ be large relative to $T B$, then $(T B+F) / F>0$. It is clear from eq. (21) that the textbook result, that a discretionary supply of foreign currency, $F>0$, causes the forward rate to appreciate, is obtained if $\phi=0$. In contrast, if volatility is sufficiently responsive to intervention, i.e. $|\phi|>F /(T B+F)$, then $\operatorname{sign}(\mathrm{d} f / \mathrm{d} F)=-\operatorname{sign}(\phi)$ and a sign reversal for the effect of intervention can occur. A priori not much can be said about sign $(\phi)$. But suppose for example that $\phi$ is negative, then eq. (21) shows that $f$ depreciates with more intervention if $\Omega$ is positive. By Lemma 2 it then follows that intervention always benefits exports and harms imports. Without further hypothesizing about central bank behavior and the signs of $\varepsilon_{F}$ and $\sigma_{F}^{2}$, not much more can be said other than pointing out that $f, \varepsilon, \sigma^{2}$ and $F$ are related through eq. (20). But note, however, that we still have the robust result implied by Lemma 2 that $\partial X / \partial F=-\partial Y / \partial F$. Official intervention cannot serve two masters at the same time.

\section{Conclusions}

This paper investigated how changes in the mean exchange rate and its volatility affect trade flows. It was shown how important it is to derive the equilibrium implications of a forward market. While the predictions for changes in the mean corroborate the conventional terms of trade effect, changes in volatility have different impacts depending on whether or not a forward market exists; and, in the case where it does exist, it matters whether the aggregate net formign currency position is positive or negative. Moreover, it was shown how a positive sign on the volatility variable in a regression for the volume of trade may be consistent with the theory. Of course, the real test for our contentious is an empirical investigation. Hopefully, the above offers a convenient framework within which the empirical analysis can be conducted.

\section{References}

Bailey, M.J., G.S. Tavlas and M. Ulan, 1986, Exchange rate variability and trade performance: Evidence for the big seven countries, Weltwirtschaftliches Archiv 3, 466-477.

Black, S.W., 1985, International money and international monetary arrangements, in: R.W. Jones and P.B. Kenen, eds., Handbook of international economics, Vol. II (North-Holland, Amsterdam) 1173-1194.

Brada, J.C. and J.A. Mendez, 1988, Exchange rate risk, exchange rate regime and the volume of international trade, Kyklos, 263-280.

Coes, D., 1981, The crawling peg and exchange rate uncertainty, in: J. Williamson, ed., Exchange rate rules: The theory, performance and prospects of the crawling peg (St. Martin's Press, New York) 113-136.

Cushman, D.O., 1983, The effects of real exchange rate risk oii international trade, Journal of Internationa! Economics 15, 45-65.

Cushman, D.O., 1988, U.S. bilateral trade flows and exchange risk during the floating periud, Journal of International Economics 24, 317-330. 
De Grauwe, P. and B. de Bellefroid, 1987, Long-run exchange rate variability ind international trade, in: S.W. Arndt and J.D. Richardson, eds., Real-financial linkages among open economies (MIT Press, Cambridge, MA), 193-212.

De Grauwe, P. and G. Verfaille, 1988, Exchange rate variability, misalignment and the European monetary system, in: R.C. Marston, ed., Misalignment of exchange rates: Effects on trade and industry (University of Chicago Press, Chicago, IL), 77-103.

Dellas, H. and B.-Z. Zilberfarb, 1989, Real exchange rate volatility and international trade: A reexamination of the theory, Mimen.

Ethier, W., 1973, International trade and the forward exchange market, American Economic Review 63, 494-503.

Feder, G., R.E. Just and A. Schmitz, 1980, Futures markets and the theory of the firm under price uncertainty, Quarterly Journal of Economics 94, 317-328.

Gotur, P., 1985, Effects of exchange rate volatility on trade, IMF Staff Papers 32, 475-512.

Grassman, S., 1973, A fundamental symmetry in international payriient patterns, Journal of International Economics 3, 105-116.

Holthausen, D.M., 1979, Hedging and the competitive firm and price competition, American Economic Review 69, 989-995.

Hooper, P. and S.W. Kohlhagen, 1978, The effect of exchange rate uncertainty on the prices and volume of international trade, Journal of International Economics 8, 483-511.

Katz, E. and J. Paroush, 1979, The effect of forward markets on exporting firms, Economics Letters 4, 271-274.

Kawai, M., 1984, The effect of forward exchange on spot-rate volatility under risk and rational expectations, Journal of International Economics 16, 155-172.

Kenen, P.B. and D. Rodrik, 1984, Measuring and analyzing the effects of short-term volaiility in real exchange rates, Working papers in international economics, G84-01 (International Finance Section, Princeton University, Princeton, NJ).

Kenen, P.B. and D. Rodrik, 1986, Measuring and analyzing the effects of short-term volatility in real exchange rates, The Review of Economics and Statistics 68, 311-315.

Pagan, A., 1984, Econometric issues in the analysis of regressions with generated .egressors, Internationa! Economic Review 25, 221-247.

Stein, J.L., 1985, Exchange rate management with rational expectations but diverse precisions, in: J.S. Bhandari, ed., Exchange rate management under uncertainty (MIT Press, Cambridge, MA) 96-125.

Steinherr, A. and E. Perée, 1989, Exchange rate uncertainty and foreign trade, European Economic Review 33, 1241-1264.

Thursby, J.G. and M.C. Thursby, 1987, Bilateral trade flows, the Linder hypothesis, and exchange risk, The Review of Economics and Statistics 69, 488-495.

Viaene, J.M. and C.G. ce Vries, 1992, On the design of invoicing practices in international trade, Open Economies Review, forthcoming. 